\title{
Back to work
}

Shaun Sellars continues his series on ethical dilemmas in dentistry which appears in every second issue of the $B D J$.

As far back as 1785, Immanuel Kant advised us to treat people 'never merely as a means to an end, but always at the same time as an end.' Throughout the COVID-19 crisis, those in control appear to have ignored this sage advice with both dental professionals and patients increasingly used as pawns in a political game.

And so, with just ten days' notice, those of us in practice were sent back to work. Since then, we've been bombarded with numerous sets of SOPs and back to work guidance. Experts and self-appointed gurus have flooded the internet with words of wisdom, some much wiser than others. I like a guideline and a protocol, but even I think that this has been a case of information overload.

Throughout the COVID-19 crisis, the amount of, often conflicting, advice thrown towards the dental community has caused confusion, dismay and anger. Some have even suggested that we should have hard and fast rules put in place by our various regulators to ensure what we are doing is correct.

Apart from this being beyond their collective remits, this is a bad idea. Once we set a precedent for regulators to provide strict guidelines, where do we stop? Currently, we're in a relatively enviable position of being allowed to practise dentistry how we see fit, within reason. Allowing regulators to dictate how we're allowed to deliver those treatments leads to a much less autonomous profession. It also makes it much easier for claims of substandard practice to be levelled at any one of us who doesn't follow those guidelines. At a time when the profession feels under fire, this will only exacerbate the ill will towards those that govern us.

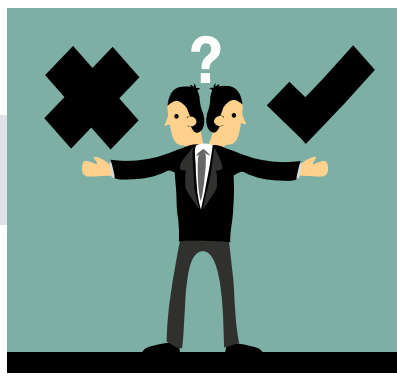

It feels as if that ill will has increased significantly since lockdown measures were enacted. The vitriol of the profession has mainly been directed at those in charge, and specifically the $\mathrm{CDO}$ of England. The messages coming from our Chief have not always been clear, and one would hope there would be lessons to be learned from this, especially in regards to engaging with the profession using social media. Significant sectors of the profession have felt alienated throughout the COVID-19 crisis, with no support from the government or their leaders. From this, new alliances have formed for the betterment of all.

The profession as a whole should also be looking inwards at itself to reflect on the nature of the discourse we have participated in recently. It's worth remembering that the CDO is as much a political position as one of a leader of healthcare. The position lends itself to be as much of a pawn in the political strategy as the rest of the profession. The bitterness of much of the commentary has been unpleasant to see, let alone be on the receiving end of. I wonder if the gender of the CDO has played any part in this?

Now is not the time to let our shield of professionalism down. Now is the time to reinforce it and become united for positive change.

\section{References}

1. Kant I, Wood A W. Groundwork of The metaphysics of morals (1785). In Gregor M J (editor) Practical Philosophy. . pp. 37-108. The Cambridge Edition of the Works of Immanuel Kant. Cambridge: Cambridge University Press 1996.

\section{Chlorhexidine has an antiviral effect against viruses}

A recently published paper in the Korean Journal of Medical Science, 'Clinical significance of a high SARS-CoV-2 viral load in the saliva', demonstrates the in vivo activity of chlorhexidine as a mouthwash against viruses. ${ }^{1}$

It suggests that the in vivo activity will last for two hours and is gone by four (and not repeatable when the mouthwash is tried again at day six) but also confirms the very high levels of SARS-CoV-2 in saliva and in the nose. The general conclusion from studies of antiviral activity of mouthwashes in vitro suggests that chlorhexidine is not as effective as povidone iodine, but this study suggests that it does have antiviral activity and could be considered as a backup.

\footnotetext{
Reference

1. Yoon J G, Yoon J, Song J Y et al. Clinical significance of a high SARS-CoV-2 viral load in the saliva. J Korean Med Sci 2020; 35: e195.
}

\section{BDA updates its returning to work toolkit for members}

The British Dental Association (BDA) has published an updated edition of its toolkit for returning to face-to-face care. It will support members and their teams to resume dental practice as safely and efficiently as possible.

The toolkit will help dental teams implement the changes needed to gear up to providing appropriate treatments at appropriate times. It is for practices in England; the BDA is working on versions for the devolved nations in line with developing frameworks.

This latest version of the toolkit [4 June] has been updated with essential information on PPE, fit-testing, respiratory protective equipment (RPE) and the furloughed workers scheme.

Members can download the toolkit and related resources at: https:// www.bda.org/advice/Coronavirus/Pages/returning-to-work.aspx. 